\title{
Evaluation of Undergraduate Students' Performance in Test and Measurement Achievement Test with Samples from Probabilistic and Non- Probabilistic Sampling Procedures
}

\author{
Patrick, U. Osadebe \\ Department of Guidance and Counselling \\ Delta State University, Abraka, Nigeria. \\ drosadebeuzo@gmail.com \\ 08035776610
}

\begin{abstract}
The study was carried out to evaluate the performance of undergraduate students in Test and Measurement Achievement test with samples from probabilistic and non-probabilistic sampling procedures. Three research questions and one hypothesis guided the study. A sample of 200 students (100 from proportionate stratified random representing probabilistic and 100 from purposive representing non-probabilistic). Test and Measurement Achievement test was the instrument used for the study. It has face and content validities. It has a reliability coefficient of 0.79 obtained through Kuder-Richardson formula 20. The data collected with the instrument were analysed in line with the research questions and hypothesis. Mean was used to answer the research questions while Z-test was used to test the hypothesis at 0.05 level of significance. The results showed that the undergraduate students who were selected through the probabilistic sampling procedure performed better than sample of students from the non-probabilistic procedure. There was a significant difference between the sample of students from probabilistic and non-probabilistic sampling procedure. Recommendations were made. It was recommended that researchers and evaluators should always use probabilistic or random sampling procedure to carry out their studies for generalisation or judgement. In addition, simple random sampling of balloting or random numbers should always be used and applied when using stratified sampling procedure to select individuals for a study.
\end{abstract}

Keywords Education, Evaluation, Sampling procedures, Test, and Measurement.

\section{INTRODUCTION}

Research generally requires the use of sample derived from population through different sampling procedures. Some researchers do not use the sampling procedures appropriately. This is a major problem that requires investigation. In research, samples and sampling techniques are used to achieve the methodology of studies carried out by researchers. A sample is obtained through different sampling techniques, it is necessary when the population is large. Therefore, a sample is part of a given population. Sampling technique is a method used in choosing a sample. There are different types of sampling techniques. These have been grouped into two, namely probabilistic and non-probabilistic sampling procedures (Nworgu, 2015; Ukwuije \& Orluwene, 2012). The categorization became necessary so that a researcher could use the appropriate technique to choose a sample or samples.

The probabilistic sampling technique implies that every member of a given population has equal opportunity of being selected through simple random sampling of balloting or random numbers. (Osadebe, 2015). The simple random sampling should be applied to the various sampling procedures. These include stratified, cluster and systematic. The study used proportionate stratified random sampling techniques representing probabilistic method. The stratified random sampling technique is subdivided into parts. These include proportionate and disproportionate. 
In proportionate random sampling technique, the selection of subjects may be based on a chosen percentage or proportion of choice based on the variables of the study. A researcher may group the subjects into strata. Assuming that gender or sex is a variable of the study. The researcher could stratify into male and female, from the population, then use a chosen percentage to select. It could be $60 \%$ male and $40 \%$ female to form strata. After the proportion, the final selection of subject should be done using simple random sampling of balloting or random numbers. This ensures that every subject has an equal opportunity of being selected. The non-proportionate random sampling does not vary the percentage used. It could be $50-50 \%$. If the variable is four strata, it could be $25 \%$ class $1 / 25 \%$ class II/ $25 \%$ class III/ $25 \%$ class IV. It should be noted that the percentage is done irrespective of the proportion of variable in the population. This made the method non-proportionate. However, the selection of subjects after the percentage is through simple random with either balloting or random numbers (Osadebe, 2014).

Apart from the probabilistic sampling method, is the non-probabilistic sampling procedure? It does not involve the use of simple random sampling technique of balloting or random numbers. There are different types. These include quota sampling, purposive sampling, and accidental sampling among others. However, the researcher used purposive sampling for the study to represent the non-probabilistic.

It has been observed that several studies such as Osadebe (2013), Enwefa (2016), Orubu (2016), Aliyu (2015) and Ekeke (2016) used only one sampling procedure to determine their results. Therefore, the use of different sampling procedures to choose samples from the same population is current. This was the gap the study covered. The researcher used samples derived from proportionate stratified random sampling, representing probabilistic sampling and purposive sampling representing non-probabilistic sampling to choose samples from the same population that were used to evaluate students' performance in Test and Measurement respectively. Test and Measurement is a core course in the university. It was considered as an achievement test.

\section{LITERATURE REVIEW}

There are different sampling procedures. These have been grouped into probabilistic and non-probabilistic sampling procedures. This categorization has been noted by Ukwuije and Orluwene (2012), Nworgu (2015), Joe (1992) Owen and Jones (1994), Spiegel, Schiller, and Srinivasan (2009). This was a theoretical presentation. Thus, it became necessary to carry out an empirical study to evaluate which procedure would be more reliable. Some researchers prefer probabilistic procedure while others prefer non-probabilistic.

Probabilistic procedures include simple random sampling, stratified random, cluster random and systematic sampling. It should be noted that sampling is the process of selecting individuals or things for a study. The probabilistic procedure provides opportunity for every individual or thing in a population, the opportunity of being selected to constitute a sample. The procedure is free from bias. It has been pointed out that a probabilistic sample is a sample in which every unit in the population has a chance of being selected in the sample (Wikipedia, 2015). It should be noted that simple random sampling of balloting or random numbers should always be used to select individuals or things while using stratified, cluster and systematic procedures.

The non-probabilistic procedure is used by some researchers. They feel that it is more convenient for them. Wikipedia (2015) pointed out that the non-probability sampling is any sampling procedure where some individuals of the population have no chance of being selected. Hence, the non-probabilistic procedures include purpose sampling, quota sampling, and accidental sampling among others. The purposive sampling was used for the study.

The focus of the study was on the evaluation of samples derived from probabilistic and nonprobabilistic procedures on students' performance in Test and Measurement Achievement test. The performance of students in any subject depends on the sampling procedure. A sampling procedure may be bias as observed by Ukwuije and Orluwene (2012), Wikipedia (2015) and Nworgu (2015).

Several studies have been carried out on Evaluation. Some of these include Osadebe (2009), Osadebe (2013) and Osadebe (2015). The previous studies used only one sample size derived from any of the sampling procedures to evaluate. This study evaluated two samples: one derived from probabilistic 
procedure and the other from non-probabilistic. The samples were used to determine students' performance in Test and Measurement Achievement test. It was a gap that the study covered. This was also a contribution to knowledge. It should be noted that Evaluation is the process of making judgement. It is also the extent to which an objective of a programme is achieved. It is a judgement derived from valid and reliable data. The data required could be obtained through the use of test, observation, questionnaire, interview among others (Osadebe, 2014). The study evaluated the performance of students with samples of students from probabilistic and non-probabilistic sample through the use of Test and Measurement Achievement test.

There are various Evaluation models required in evaluation study. These models include goal attainment, judgemental and decision facilitation. The model used in this study is judgemental model emphasizing extrinsic criteria. Scholars who laid emphasis in this area include Best and Khan (1989), Popham (1975), Worthen and Sanders (1987), Gronlund (1985), and Osadebe (2016).

The following research questions and hypothesis guided the study:

\section{RESEARCH QUESTIONS}

1. What is the performance of students in Test and Measurement Achievement test with a sample from probabilistic sampling procedure?

2. What is the performance of students in Test and Measurement Achievement test with a sample from non-probabilistic sampling procedure?

3. What is the performance of students in Test and Measurement Achievement test with a sample each from probabilistic and non-probabilistic sampling procedures?

\section{HYPOTHESIS}

1. There is no significant difference between probabilistic and non-probabilistic sample of students in their performance in Test and Measurement Achievement test.

\section{METHOD}

The study was designed to find out the achievement of undergraduate students in Test and Measurement using samples derived from probabilistic and non-probabilistic sampling procedures from the same population. It was both comparative and evaluation study. Test and Measurement is a core course taught to students in the university. The two procedures were compared and judgement made on students' performance in the test. A sample of 100 each was selected from proportionate stratified random sampling, representing probabilistic and purposive sampling representing non-probabilistic procedure. The samples were drawn from the same population. The total sample was 200 (100 for probabilistic and 100 for non-probabilistic).The samples were made up of undergraduate students. The sampling procedures were used to select the students respectively. The name of each student was not repeated in any group.

The instrument of the study was a Test and Measurement Achievement Test (TAMAT) designed by the University lecturers who are experts in Measurement and Evaluation. The instrument has face and content validities. It has a reliability coefficient of 0.79 obtained through Kuder-Richardson formula 20. The instrument was considered valid and reliable before it was administered to students. 
The data collected were analysed in line with the research questions and hypothesis. The research questions were answered with the use of mean. A mean of 60 and above was evaluated as high performance while a mean below 60 was evaluated as low performance. Z-test was used to test the hypothesis at 0.05 level of significance.

\section{RESULTS}

The results were presented in line the research questions and hypothesis.

Research Question one: What is the performance of students in Test and Measurement Achievement test with a sample from probabilistic sampling procedure?

Table 1 Mean analysis of students' performance in Test and Measurement with a sample from probabilistic sampling procedure.

\begin{tabular}{llllll}
\hline $\begin{array}{l}\text { Probabilistic } \\
\text { sampling } \\
\text { procedure }\end{array}$ & $\begin{array}{l}\text { Sampling } \\
\text { Size }\end{array}$ & Total Score & Mean & Benchmark & Evaluation \\
\hline $\begin{array}{l}\text { Proportionate } \\
\begin{array}{l}\text { Stratified } \\
\text { S }\end{array}\end{array}$ & 100 & 6601 & 66.01 & 60 & High
\end{tabular}

The table 1 showed that the calculated mean of 66.01 was higher than the benchmark of 60 for evaluation. The result revealed that the performance of students in Test and Measurement Achievement test using a sample derived from probabilistic procedure was high.

Research Question Two: What is the performance of students in Test and Measurement Achievement test with a sample from non-probabilistic sampling procedure?

Table 2 Mean analysis of students' performance in Test and Measurement Achievement test with a sample from non-probabilistic sampling procedure.

\begin{tabular}{llllll}
\hline $\begin{array}{l}\text { Non-Probabilistic } \\
\text { sampling procedure }\end{array}$ & $\begin{array}{l}\text { Sampling } \\
\text { Size }\end{array}$ & $\begin{array}{l}\text { Total } \\
\text { Score }\end{array}$ & Mean & Benchmark & Evaluation \\
\hline Purposive & 100 & 5880 & 58.80 & 60 & Low \\
\hline
\end{tabular}

The table 2 indicated that the calculated mean of 58.80 was lower than the benchmark of 60 for evaluation. The result showed that the performance of students in Test and Measurement Achievement test with a sample derived from non-probabilistic procedure was low.

Research Question Three: What is the performance of students in Test and Measurement Achievement test with a sample each from probabilistic and non-probabilistic sampling procedures?

Table 3 Mean analysis of students' performance with a sample each from probabilistic and non-probabilistic sampling procedures

\begin{tabular}{llllll}
\hline Sampling procedure & Sampling Size & Total Score & Mean & $\begin{array}{l}\text { Benchma } \\
\text { rk }\end{array}$ & Evaluation \\
\hline Probabilistic & 100 & 6601 & 66.01 & 60 & High \\
Non-probabilistic & 100 & 5880 & 58.80 & & Low \\
Total & 200 & & & \\
\hline
\end{tabular}


The table 3 showed that a mean of 66.01 was for students' performance in Test and Measurement Achievement test derived from probabilistic sampling procedure while a mean of 58.80 was from nonprobabilistic. The probabilistic mean of 66.01 was above the benchmark of 60 for evaluation while the non-probabilistic mean of 58.80 was below the benchmark of 60 for evaluation. The result revealed that students performed better with a sample from probabilistic sampling procedure.

Hypothesis One: There is no significant difference between probabilistic and non-probabilistic sample of students in their performance in Test and Measurement Achievement test.

Table 4 Z-test analysis on students' performance in Test and Measurement Achievement test using samples from probabilistic and non-probabilistic sampling procedures.

\begin{tabular}{lccclll}
\hline Sampling Procedure & N & Mean & SD & $\begin{array}{l}\text { Cal. } \\
\text { Z-Value }\end{array}$ & $\begin{array}{l}\text { Crit. } \\
\text { Z-Value }\end{array}$ & Evaluation \\
\hline Probabilistic & 100 & 66.01 & 8.5 & & & \\
Non-probabilistic & 100 & 58.80 & 9.1 & $\mathbf{5 . 8 1}$ & $\mathbf{1 . 9 6}$ & $\begin{array}{l}\text { Rejected } \\
\text { (significant) }\end{array}$ \\
Total & 200 & & & & & \\
\hline
\end{tabular}

$\mathbf{P}<0.05$

The table 4 showed that the calculated Z-value of 5.81 was higher than the critical Z-value of 1.96 at 0.05 level of significance. The null hypothesis was rejected. Hence, the result revealed that there was a significant difference between students' performance in Test and Measurement Achievement test from samples derived from probabilistic and non-probabilistic sampling procedures. The probabilistic sampling procedure was better.

\section{DISCUSSION}

The result of the study revealed that students sampled with probabilistic sampling procedure perform better in Test and Measurement Achievement test than the sample of students from non-probabilistic. Probabilistic sampling applies to proportionate stratified random. Non-probabilistic was limited to purposive. The result was similar to the study of Omole (2007), Osadebe (2009), Osadebe (2013) who used probabilistic sample of students to assess students' performance. The study was also in line with the recommendations of Ukwuije and Orluwene (2012), Nworgu (2015) and Wikipedia (2015) that probabilistic sampling procedure should be used because it is valid, more reliable, and free from bias. However, the study was at variance with Osadebe (2015) who use probabilistic sampling procedure.

\section{RECOMMENDATIONS}

The following recommendations were made from the study:

1. Researchers should use probabilistic sampling procedure in selecting the subjects or things for their studies because it is valid, reliable and free from bias.

2. Simple random sampling of balloting or random numbers should always be used and applied when using stratified sampling procedure for individuals or things for a study. 


\section{CONCLUSION}

The study was carried out to find out the performance of students in Test and Measurement Achievement Test (TAMAT) using stratified random representing probabilistic procedure and purposive sampling representing non-probabilistic. It was found that the sample of students from probabilistic sampling procedure performed better in the test.

Probabilistic sampling procedure used was the proportionate stratified while that of nonprobabilistic was the purposive sampling. Some researchers use non-probabilistic sampling procedure because of interest, but this study found probabilistic sampling procedure as more valid, reliable and not bias. Therefore, it should always be used.

\section{ACKNOWLEDGEMENT}

The researcher is grateful to his wife, Mrs. J.F. Osadebe for her contribution to the publication of this research work.

\section{REFERENCES}

Aliyu, R. T. (2015). Development and validation of Mathematics achievement test using Rasch model. Unpublished Ph.D. Thesis, Delta State University, Abraka.

Best, J. K \& Khan, J. V. (1989). Research in Education. Englewood Cliffs, N. J. Prentice- Hall. Inc.

Ekeke, A. U. O. (2016). Environmental factors as correlates of senior secondary school students' cognitive achievement in Biology in Delta and Edo States. Unpublished Ph.D. Thesis, Delta State University, Abraka.

Enwefa, C. (2016). Evaluation of teachers' use of information and communication technology in teaching at Basic Education level in South-South Nigeria. Unpublished Ph.D. Thesis, Delta State University, Abraka.

Gronlund, N. E. ( 1985). Measurement and Evaluation in teaching ( $5^{\text {th }}$ Ed.) New York: Macmillian Publishers.

Joe, A. I. (1992). Fundamental statistics for education and behavioural sciences. Ibadan: Kraft Books limited.

Nworgu, B. G. (2015). Educational research: Basic issues \& methodology $\left(3^{\text {rd }}\right.$ Ed). Nsukka: Universal Trust Publishers.

Omole, D. O. K. (2007). Comparative study of students' performance in school-based assessment and certificate examination at the upper basic education level in FCT. Nigeria Journal of Educational Research and Evaluation, 7 (1), 50-56.

Orubu, M. N. (2016). Junior secondary certificate examination scores in Mathematics and Integrated Sciences as predictors of senior secondary school students' performance in science. Unpublished Ph.D. Thesis, Delta State University.

Osadebe, P. U. (2009). Evaluation of students' academic performance in senior secondary schools with counselling services. African Journal of Education and Developmental Studies, 6(1), 142-150.

Osadebe, P. U. (2013). Evaluation of human capital development in Delta State. African Journal of Social Sciences, 3(3), 186-193.

Osadebe, P. U. (2014). Evaluation of achievement of Universal Basic Education (UBE) in Delta State. Education, $134(3), 419-424$

Osadebe, P. U. (2015). Comparative analysis of senior secondary school students' performance with school-based assessment scores of continuous assessment and promotion examination in Delta State. International Journal of Education, 7(1), 154-164.

Osadebe, P. U. (2016). Evaluation Models: A Seminar Paper presented at Delta State University, Abraka.

Owen, F., \& Jones, R. (1994). Statistics. London: Longman Group UK limited.

Popham, J. W. (1975). Educational evaluation. New Jersey: Pretence Hall Inc.

Spiegel, M. R., Schiller, J., \& Srinivasan, R. A. (2009). Schaum's outline of probability and statistics. US: Mc Graw-Hill Companies. Inc.

Ukwuije, R. P. I. \& Orluwene, G. W. (2012). Peanuts educational statistics. PortHarcourt: Chadik Printing Press.

Wikipedia (2015). Sampling (statistics). Retrieve on 15/5/2016 from http://en.wikipedia.org/wiki/sampling (statistics).

Worthen, B. R., \& Sanders, J. R. (1987). Educational evaluation. New York: Longman Publishers. 